\title{
Interpretation of High Resolution Aeromagnetic Data for Hydrocarbon Potentials over Parts of Nasarawa and Environs North-Central Nigeria
}

\author{
Rowland Akuzigi Ayuba*, Ahmed Nur \\ Department of Geology, Moddibbo Adama University of Technology Yola, Adamawa State, Nigeria \\ Email address: \\ akuzigi@yahoo.com (R. A. Ayuba), anur07@gmail.com (A. Nur) \\ ${ }^{*}$ Corresponding author \\ To cite this article: \\ Rowland Akuzigi Ayuba, Ahmed Nur. Interpretation of High Resolution Aeromagnetic Data for Hydrocarbon Potentials over Parts of \\ Nasarawa and Environs North-Central Nigeria. World Journal of Applied Physics. Vol. 4, No. 1, 2019, pp. 1-11. \\ doi: 10.11648/j.wjap.20190401.11
}

Received: June 20, 2018; Accepted: August 1, 2018; Published: May 29, 2019

\begin{abstract}
Spectral depth analysis over parts of Nasarawa area was carried out using high resolution aeromagnetic data to determine the depth to bottom of magnetic sources, to enable build up a subsurface picture of basement configuration and possible sediments distribution that promote hydrocarbon exploration in the area. The study revealed one and in most cases two source model, these are the deep magnetic anomaly sources and the shallow magnetic anomaly sources. The deep sources anomalies vary between $2.23 \mathrm{~km}$ and $5.11 \mathrm{~km}$ with an average depth of $3.05 \mathrm{~km}$ and this represents the magnetic basement depth. The shallow anomaly sources vary from $0.07 \mathrm{~km}$ to $0.42 \mathrm{~km}$ with an average of $0.21 \mathrm{~km}$ and this may be regarded as the magnetic intrusions into the sediment, probably through the magmatic activities. The revelation from this study of $3.05 \mathrm{~km}$ magnetic basement depth at the southern part of the area is synonymous to depth of Cretaceous sediment, which is very significant to hydrocarbon generation potential in the area. The result shows the graben nature and indicated the existence of a deeper sub basin in the area. The central and south-western parts with higher sedimentary thicknesses are the most probable sites for hydrocarbon accumulation.
\end{abstract}

Keywords: Magnetic Anomaly, Basement Depth, Nasarawa, Hydrocarbon Potential

\section{Introduction}

The Benue Trough is part of an early cretaceous rift complex known as the west and central African Rift system, whose development was closely associated with the separation of Africa from South America in the Aptian [8]; and the opening of the Atlantic Ocean, this separation led to the development of the Triple junction (RRF) characterized by South Atlantic Margin, the Gulf of Guinea and the Benue Trough, It extends NNE-SSW for about $800 \mathrm{~km}$ in length and $150 \mathrm{~km}$ in width. The southern limit is the northern boundary of the Niger Delta, while the northern limit is the southern boundary of the Chad Basin. The Trough has been categorized into three different zones and they are: the Lower Benue Trough at the southern part, the Middle Benue Trough at the centre, while the Upper Benue Trough is at the Northern part
In recent years, there have been debates and arguments whether the shale rocks in the middle Benue Trough are thermally mature to generate hydrocarbon or show potential to generate gas in the deeper sections. This is because the oil companies have so far not encountered hydrocarbon in the Middle Benue Trough this could be due to inadequate technology, faulty work programme and poor knowledge of their geology. The present work is necessitated by the need to explore other areas suspected to have potential for hydrocarbon to make up for the depleting resources in Niger Delta and also due to topographic and security challenges as a result of youth restiveness that has reduced production base which brought untold hardship that almost cripple Nigeria's economy, this has been a major source of concern to all and sundry.

In this paper we attempt to carry out geophysical investigation in area around the Trough using the magnetic 
method. This is with a view of obtaining information on the

hydrocarbon potentials of the area through their effects on the aeromagnetic data. Aeromagnetic method can be used to map magnetic features within sedimentary basins of the Earth's crust such as geologic faults, magnetic bodies associated with mineral deposits, and basin structures associated with oil and gas accumulations, basins fills typically has lower susceptibilities than crystalline basement. Thus it is possible to estimate the depth to basement and, under favourable condition, qualitatively map basement structures such as faults, horst blocks and grabens. It believed that interpretation of the high resolution aeromagnetic magnetic fields over parts of Benue Trough, using relevant control, will, to a very reasonable extent, reveal the possibility of exploiting hydrocarbon in the area.

\section{Location of the Study Area}

The study area is located in the northcentral Nigeria, it is bounded by latitudes $7^{0} 30^{\prime} \mathrm{N}$ and $9^{0} 30^{\prime} \mathrm{N}$ and longitudes $8^{0}$ $00^{\circ} \mathrm{E}$ and $10^{\circ} 00^{\circ} \mathrm{E}$. The area it is part of the Middle Benue Trough that borders the basement complex rocks of northcentral Nigeria, it covers an area of about $48,400 \mathrm{~km}^{2}$.
The towns bordering the area include Jos Plateau to the North, Takum to the South, Wase to the East and Keffi to the West. The area is fairly accessible and has relatively good network of roads, foot paths and tracks. Major roads found in this area provide access road to the southeastern part of Nigeria and some other communities in the study area such as Akwanga, Nasarawa-Eggon, Lafia, Keana, Awe, Doma, Shendam, Pankshin to mention few. The vegetation of the study area could be best described as Guinea Savanna type. The area is marked by two distinct climatic conditions, temperatures range from $20^{\circ} \mathrm{C}-27^{\circ} \mathrm{C}$, while at night, temperatures could be as low as $10^{\circ} \mathrm{C}$ [2]. Months of March to June experienced increasing temperatures as the rainy season set in sometimes daily temperature could be above $35^{\circ} \mathrm{C}$. The rainy season lasts usually from May/June to September/October depending on the rainfall pattern for the particular year, with mean annual rainfall of $1560 \mathrm{~mm}$. The dry season is usually heralded annually by the dry, cold Harmattan winds and occurs between November and March. After the departure of the Harmattan and in the absence of rain, the hot sunny season with temperatures exceeding $27^{\circ} \mathrm{C}$ sets in [2]. The mean annual temperature of the area is $20^{\circ} \mathrm{C}$.

\section{Geology of the Study Area}

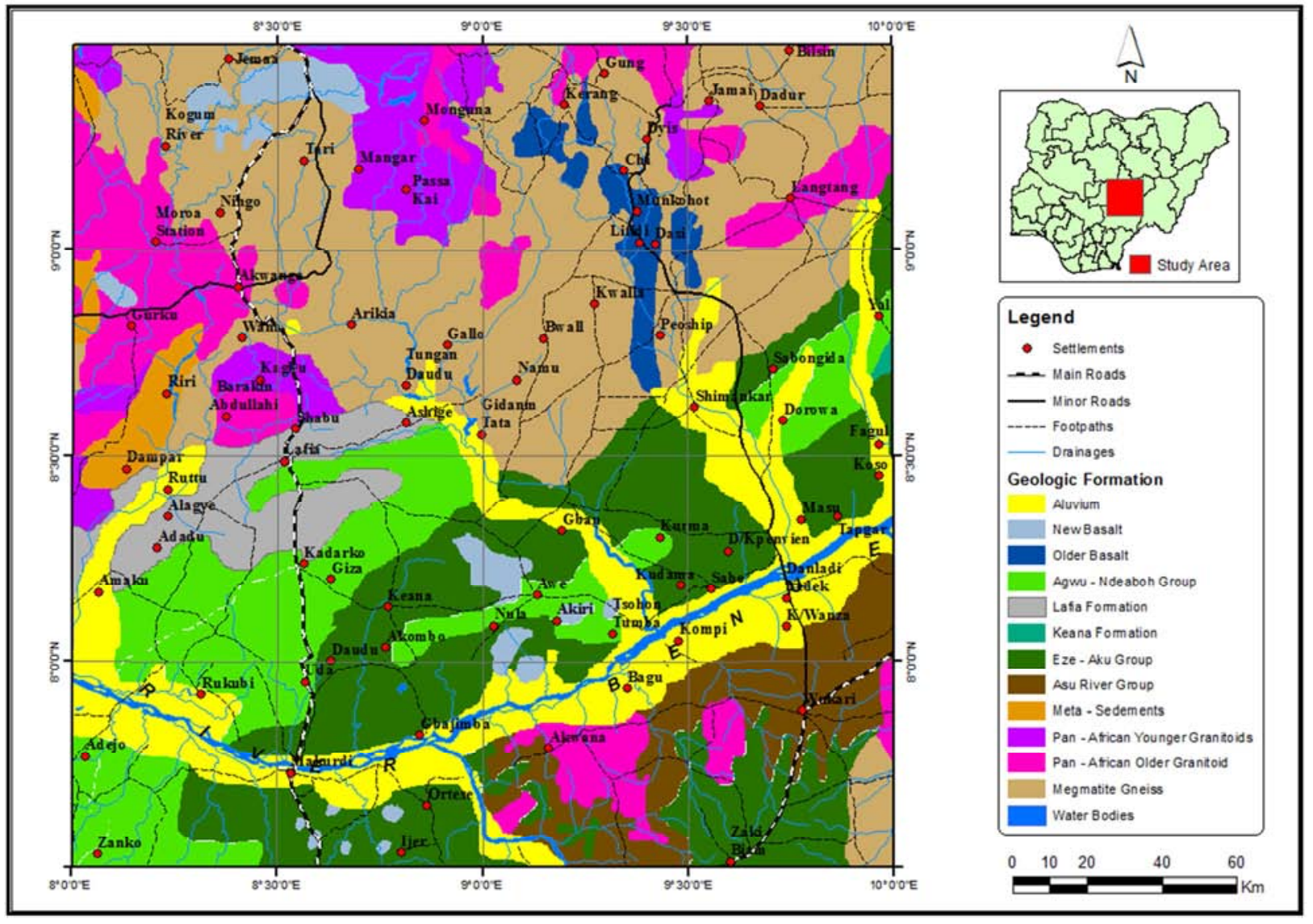

Figure 1. Geological map of the study area (Adapted from [13]).

The geology of the Middle Benue Trough (MBT) has been described in some details by [27]. The oldest rocks belong to the Asu River Group: a mixture of lava-flows, dykes and sills representing the first middle Albian episode into the Benue 
Trough. The Awe Formation marks the beginning of the regressive phase of the Albian Sea, it consists of transitional beds of flaggy, whitish, medium to coarse-grained sandstones interbedded with carbonaceous shales or clays from which brine springs issue continuously [7]. The Keana Formation resulted from the Cenomanian regression, which deposited fluviodeltaic sediments in the Lafia-Awe area. This formation consists mainly of crossbedded, coarse-grained feldspathic sandstones. The sandstone is generally poorly sorted and occasionally contains conglomerates and bands of shales and limestones towards the top. Eze aku, Agwu and Lafia Formations are also present and these represent the Turonian to Early Maastrichtian sediments in the MBT. The Ezeaku Formation comprises essentially of calcereous shale, micaceous fine to medium-grained friable sandstones, with occasional beds of limestone. The Conician Agwu Formation consists mainly of black shale, sandstones and local coal seams. The Maastrichtian Lafia Formation is the youngest formation reported in the Middle Benue Trough and consists of coarse-grain ferruginous sandstones, red loose sand, flaggy mudstones and clays [27]. The basement complex are also present in the study area (Figure 1) These basement complex rocks are of Precambrian age and consist mainly of granulitic gneisses, migmatite and older granite. The Jurassic (145-210Ma) Younger granites in the study area are high level, anorogenic granites; they mainly consist of microgranites and biotite granites, porphyries and rhyolites which outcrop at the northern fringes. Tertiary- Recent volcanic rocks which consist of the Basalts, Trachyte, Rhyolite, and newer basalts of Sura volcanic line also occur in the area.

\section{Materials and Method}

The high resolution aeromagnetic data (HRAM) used for this present work was obtained from the Nigerian Geological survey agency Abuja, [14], The airborne survey was carried out for the Nigerian Geological Survey Agency by Fugro airways services, the surveys was flown at $500 \mathrm{~m}$ line spacing and at an average flight elevation of $80 \mathrm{~m}$ along NW - SE direction, and published in form of grid (digital form) on $30^{\circ}$ by 30 ' sheets. The IGRF has been removed from the data. Sixteen sheets were assembled for this work with each square block representing a map in the scale of $1: 100,000$. Each square block is about $55 \times 55 \mathrm{~km}^{2}$ covering an area of $3,025 \mathrm{~km}^{2}$ hence the total area studied is about $48,400 \mathrm{~km}^{2}$, the digital data was acquired as merged unified block from which the sixteen sheets are windowed after a polygon had been created by means of a computer program Oasis montage version 7.5.

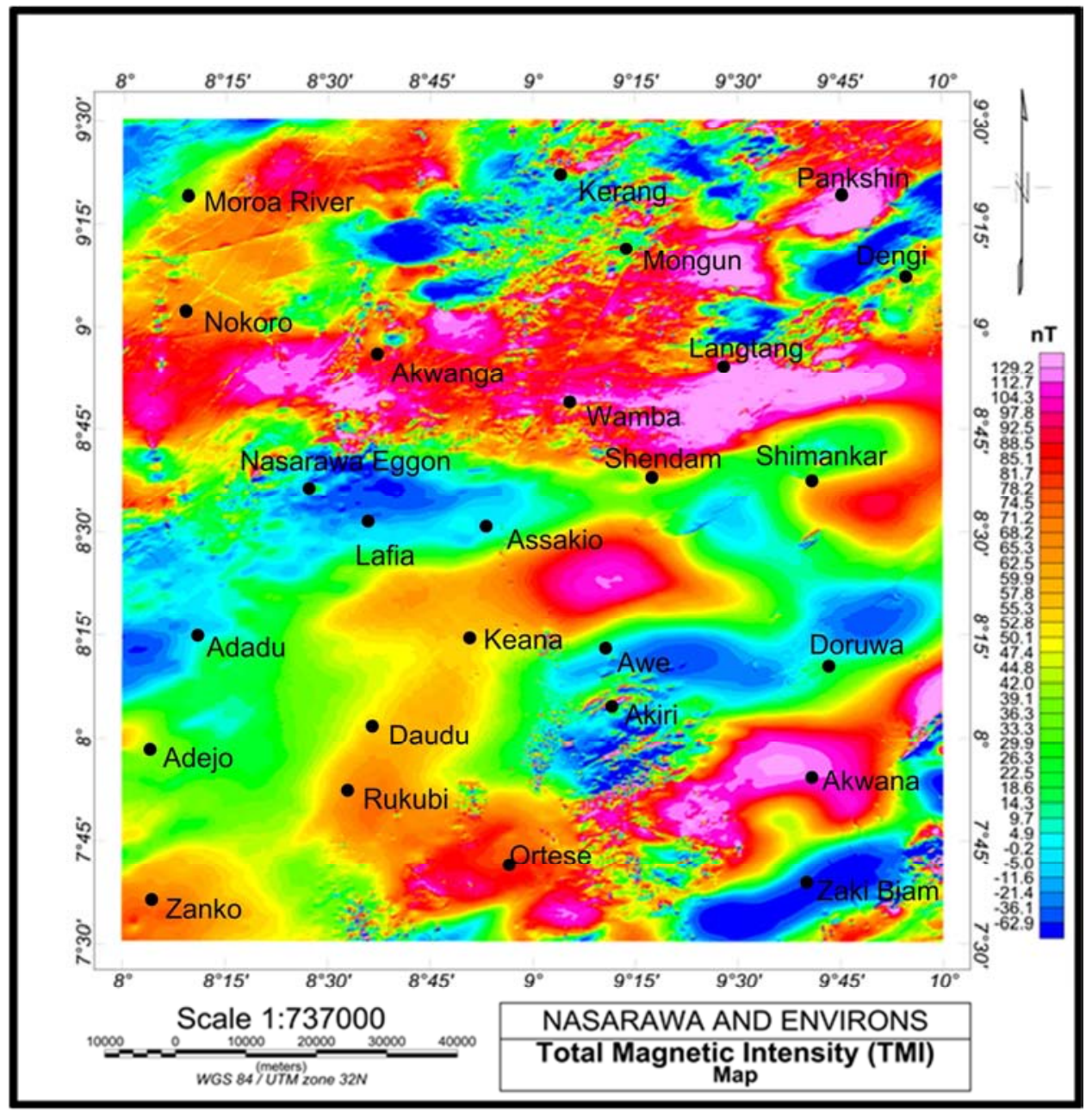

Figure 2. Total Magnetic Intensity Grid Map of the Study Area. 


\section{Spectral Analysis}

Determination of depth to magnetic sources through Spectral analysis technique is well known. The application of the power spectrum method to potential field data was first proposed by [4] and the determination of the anomalous body depth was given by [29]. This method has been used extensively by many researchers like [12, 26, 15-17, 31, 19]. It is based on the principle that a magnetic field measured at the surface can be considered the integrals of magnetic signatures from all depths. The power spectrum of the surface field can be used to identify average depths of source ensembles.

The Fourier transformation method was used for estimating the depth to magnetic sources in this research work. The two dimensional Fourier transform pair may be written as in eqn 1 and $2[4,3]$ :

$$
G(u, v)=\iint_{-\infty}^{\infty} g(x, y) e^{i(U x-V y)} \mathrm{dxdy}
$$

and

$$
G(x, y)=\frac{1}{4 \pi^{2}} \iint_{-\infty}^{\infty} g(u, v) e^{i(U x-V y)} d u d v \ldots
$$

Where $\mathrm{u}$ and $\mathrm{v}$ are the angular frequencies in $\mathrm{x}$ and $\mathrm{y}$ directions respectively. $\mathrm{G}(\mathrm{u}, \mathrm{v})$ when broken up into its real and imaginary parts is given as in eqn 3 .

$$
\mathrm{G}(\mathrm{u}, \mathrm{v})=\mathrm{P}(\mathrm{u}, \mathrm{v})+\mathrm{iQ}(\mathrm{u}, \mathrm{v})
$$

The energy spectrum is given by eqn 1.4

$$
\mathrm{E}(\mathrm{u}, \mathrm{v})=[\mathrm{G}(\mathrm{u}, \mathrm{v})]^{2}=\left(\mathrm{P}^{2}+\mathrm{Q}^{2}\right)
$$

Relating the energy spectrum with the depth of the magnetic source:

Expression for the energy spectrum in polar form [29]: follows that:

If $\mathrm{r}=\left(\mathrm{u}^{2}+\mathrm{v}^{2}\right)$ and $\Theta=\arctan (\mathrm{u} / \mathrm{v})$

The energy spectrum $E(r, \Theta)$ could be given by

$$
\begin{gathered}
\mathrm{E}(\mathrm{r}, \Theta)=4^{2} \mathrm{~K}^{2} \mathrm{e}^{-2 \mathrm{hr}}(1-\mathrm{e}-\mathrm{tr}) \mathrm{S}^{2}(\mathrm{r}-\theta) \\
\mathrm{R}^{2} \mathrm{~T}(\Theta) \mathrm{R}^{2} \mathrm{k}(\Theta) . \\
\text { Where; } \mathrm{S}(r, \theta)=\frac{\sin (\operatorname{arcos}(\theta))}{\operatorname{ar} \cos (\theta)}=\frac{\sin (\operatorname{brCos}(\theta))}{\operatorname{brCos}(\theta)} \\
R_{T}^{2}(\theta)=\left[\mathrm{n}^{2}+(1 \cos (\theta)+\mathrm{M} \sin (\theta))^{2}\right] \\
R_{k}^{2}(\theta)=\left[\mathrm{N}^{2}+(\operatorname{Lcos}(\theta)+\mathrm{M} \sin (\theta))^{2}\right] \\
<\mathrm{ECr}>=4 \pi^{2} \mathrm{~K}^{2}<1^{-2 \mathrm{tr}}><(1-1-\mathrm{tr})^{2}><\mathrm{S}^{2}(\mathrm{r})> \\
<\mathrm{S} 2(\mathrm{r})>=\frac{1}{\pi} \int_{1}^{\pi}<S(r, \theta)>d \theta .
\end{gathered}
$$

The ensemble average depth $\mathrm{h}$ enters only into the factor from the energy spectrum as shown by eqn 5 .

$$
<1-2 h r>=\frac{1^{-2 h r s} \sin h(2 r \Delta h)}{4 r \Delta t}
$$

For depth estimations for magnetic field data this was approximated to eqn 1.6

$$
E(u, v)=\exp (-2 h r)[29] .
$$

The exp (-2hr) term is the dominant factor in the power spectrum. The average spectrum of the partial waves falling within this frequency range is calculated and the resulting values together constitute the redial spectrum of the anomalous field. If we replace $h$ with $\mathrm{Z}$ and $\mathrm{r}$ with $\mathrm{f}$; then

$$
\log E=-2 Z f
$$

Where $\mathrm{Z}$ is the required anomalous depth; and f frequency. Therefore the linear graph of loge against $f$ leaves slope $(m)$ $=-2 Z$. The mean depth $(\mathrm{Z})$ of the magnetic source is thus given by eqn 8 .

$$
\mathrm{Z}=\mathrm{m} / 2
$$

The ensemble average depth $\mathrm{h}$ enters only into the factor.

$$
\frac{e^{2 h r} \sin h(2 r \Delta h)}{4 \mathrm{r} \Delta \mathrm{h}}
$$

Finally, a plot the logarithm of the energy values versus frequency on linear segments is obtained. if $\mathrm{z}$ is the mean depth of a layer the depth factor for this ensemble of anomalies is exp $(-2 z K)$. Thus, the logarithm plot of the radial spectrum would give a straight line whose slope is $-2 z$. The mean depth of burial of the emsemble is thus given as:

$$
\mathrm{Z}=-\mathrm{m} / \mathrm{z}
$$

Where $\mathrm{m}$ is the slope of the best fitting straight line. Equation (1.9) can be applied directly if the frequency unit is in radians per kilometre. If however, the frequency unit is in cycles per kilometre, the corresponding relation can be expressed as:

$$
\mathrm{Z}=-\mathrm{m} / 4 \pi
$$

To remove the regional magnetic field, which is the anomalies associated with low frequency components, a plane surface was fitted to the digital data by polynomial fitting least square analysis. In this method, the matching of regional by a polynomial surface of low order exposed the residual features as a random error, the treatment is based on statistical theory. The observed data are used to compute, usually by least squares, the mathematically describable surface giving the closest fit to the magnetic field that can be obtained within a specified degree of detail [28]; [9] and [6]. This surface is considered to be the regional and the residual is the difference between the magnetic field value as actually mapped and the regional field value, thus determined [30]. 


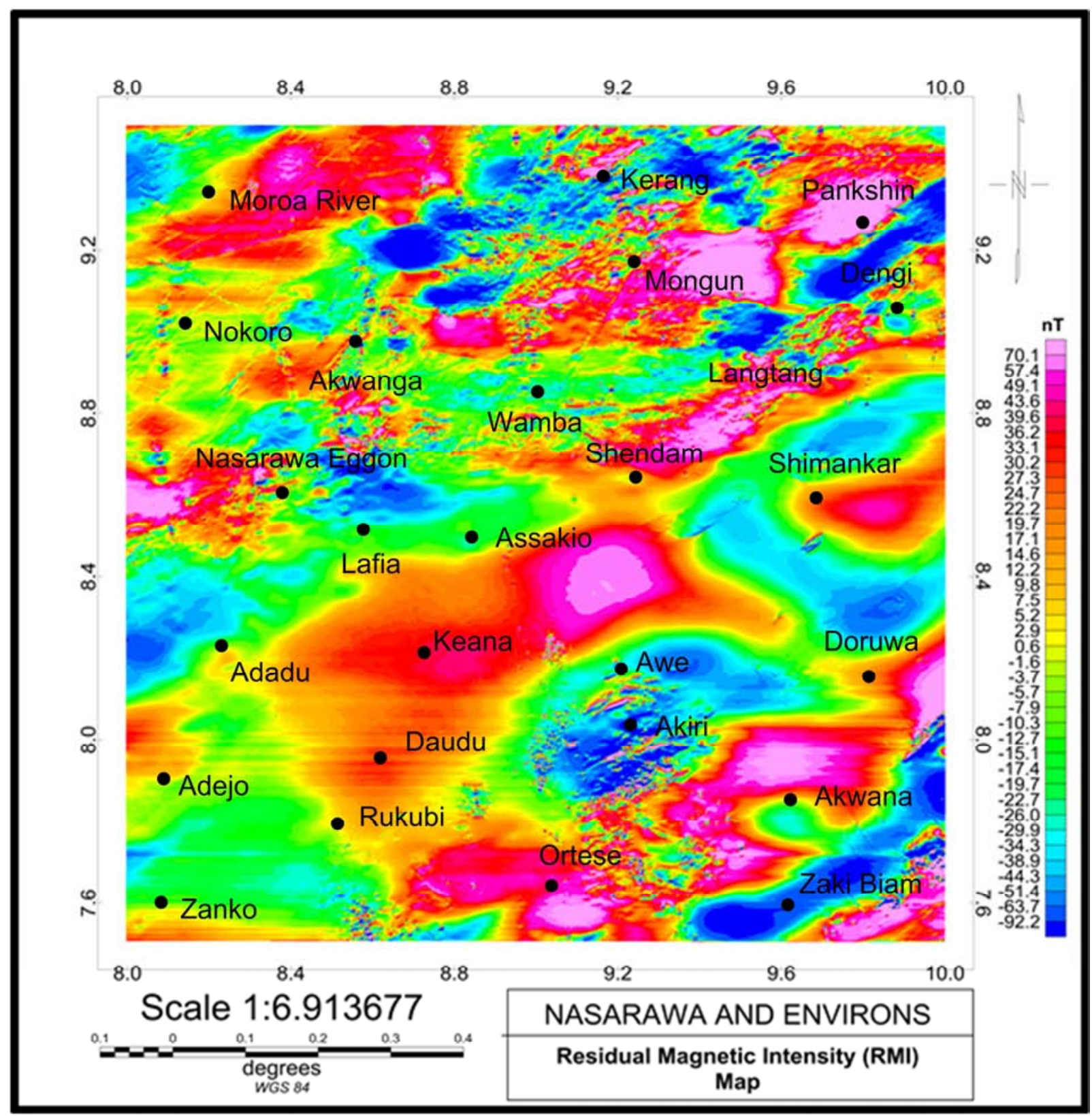

Figure 3. Residual Magnetic Intensity Grid Map of the Study Area.

To carry out the spectral analysis of the aeromagnetic data, the residual data was subdivided into 64 spectral blocks allowing spectral probe of $27.5 \mathrm{~km}$ by $27.5 \mathrm{~km}$ area for 15 minute by 15 minute windowing, for the purpose of easier handling of the large data involved, in order to accommodate longer wavelength, so that a distance of about $27 \mathrm{~km}$ could be investigated. The digital signal processing software employing the fast Fourier transform technique was used to transform the residual magnetic data into the radial energy spectrum for each block. The average radial power spectrum was calculated and displayed in a semi-log figure of amplitude versus frequency. For most cells two linear segments were identified and in some cases one, which implies that there are at most two magnetic source layers in the study area.
The gradients of each of the line segments were evaluated by means of a computer program written in matlab. The first layer $\left(D_{1}\right)$ which correspond to the deeper sources, vary between $1.09 \mathrm{~km}$ and $5.11 \mathrm{~km}$ with an average depth of 3.10 $\mathrm{km}$ and this represents the magnetic basement depth, the second layer $\left(\mathrm{D}_{2}\right)$ which correspond to the shallow sources, varies from $0.07 \mathrm{~km}$ to $0.42 \mathrm{~km}$ with an average of $0.21 \mathrm{~km}$ and this may be regarded as the magnetic intrusions into the sediment. The results of the depth to magnetic sources indicate that areas around Rukubi in the south western and Akwana in the south eastern part have sedimentary thickness of about $5.11 \mathrm{~km}$ and $4.01 \mathrm{~km}$, the result shows the graben nature of the area and indicated the existence of a deeper sub basin in this area. The depth estimates (D1 and D2) for each of the sixty four spectral blocks are given in table 1 below. 
Table 1. Summary of the depths for different blocks obtained for the entire area. All depths $D_{1}$ and $D_{2}$ are in $\mathrm{km}$.

\begin{tabular}{|c|c|c|c|c|c|c|c|}
\hline BLOCK64 & BLOCK63 & BLOCK62 & BLOCK61 & BLOCK60 & BLOCK59 & BLOCK58 & BLOCK57 \\
\hline $\mathrm{D} 1=0.44$ & $\begin{array}{l}\mathrm{D} 1=0.63 \\
\mathrm{D} 2=0.33\end{array}$ & $\mathrm{D} 1=0.35$ & $\begin{array}{l}\mathrm{D} 1=0.36 \\
\mathrm{D} 2=0.31\end{array}$ & $\mathrm{D} 1=0.36$ & $\mathrm{D} 1=0 . .38$ & $\mathrm{D} 1=0.41$ & $\mathrm{D} 1=0.40$ \\
\hline BLOCK49 & BLOCK50 & BLOCK51 & BLOCK52 & BLOCK53 & BLOCK54 & BLOCK55 & BLOCK56 \\
\hline $\mathrm{D} 1=0.38$ & $\mathrm{D} 1=0.33$ & $\mathrm{D} 1=0.31$ & $\mathrm{D} 1=0.35$ & $\mathrm{D} 1=0.36$ & $\mathrm{D} 1=0.37$ & $\mathrm{D} 1=0.39$ & $\mathrm{D} 1=1.38$ \\
\hline BLOCK48 & BLOCK47 & BLOCK46 & BLOCK45 & BLOCK 44 & BLOCK43 & BLOCK42 & BLOCK41 \\
\hline $\mathrm{D} 1=0.35$ & $\mathrm{D} 1=0.67$ & $\mathrm{D} 1=0.36$ & $\mathrm{D} 1=0.38$ & $\mathrm{D} 1=0.36$ & $\begin{array}{l}\mathrm{D} 1=1.09 \\
\mathrm{D} 2=0.28\end{array}$ & $\mathrm{D} 1=0.36$ & $\mathrm{D} 1=0.38$ \\
\hline BLOCK33 & BLOCK34 & BLOCK35 & BLOCK36 & BLOCK 37 & BLOCK38 & BLOCK39 & BLOCK40 \\
\hline $\mathrm{D} 1=1.78$ & $\mathrm{D} 1=1.18$ & $\mathrm{D} 1=3.03$ & $\mathrm{D} 1=5.06$ & $\mathrm{D} 1=3.18$ & $\mathrm{D} 1=3.41$ & $\mathrm{D} 1=3.31$ & $\mathrm{D} 1=4.00$ \\
\hline $\mathrm{D} 2=0.35$ & $\mathrm{D} 2=0.33$ & $\mathrm{D} 2=0.35$ & $\mathrm{D} 2=0.57$ & $\mathrm{D} 2=0.33$ & $\mathrm{D} 2=0.33$ & $\mathrm{D} 2=0.34$ & $\mathrm{D} 2=0.32$ \\
\hline BLOCK32 & BLOCK31 & BLOCK 30 & BLOCK29 & BLOCK28 & BLOCK27 & BLOCK26 & BLOCK 25 \\
\hline $\mathrm{D} 1=4.76$ & $\mathrm{D} 1=2.09$ & $\mathrm{D} 1=3.29$ & $\mathrm{D} 1=3.57$ & $\mathrm{D} 1=3.97$ & $\mathrm{D} 1=3.41$ & $\mathrm{D} 1=3.28$ & $\mathrm{D} 1=3.30$ \\
\hline $\mathrm{D} 2=0.34$ & $\mathrm{D} 2=0.40$ & $\mathrm{D} 2=0.27$ & $\mathrm{D} 2=0.28$ & $\mathrm{D} 2=0.28$ & $\mathrm{D} 2=0.48$ & $\mathrm{D} 2=0.29$ & $\mathrm{D} 2=0.33$ \\
\hline BLOCK17 & BLOCK18 & BLOCK19 & BLOCK20 & BLOCK21 & BLOCK22 & BLOCK23 & BLOCK24 \\
\hline $\mathrm{D} 1=2.93$ & $\mathrm{D} 1=2.13$ & $\mathrm{D} 1=3.14$ & $\mathrm{D} 1=3.77$ & $\mathrm{D} 1=3.60$ & $\mathrm{D} 1=3.17$ & $\mathrm{D} 1=3.35$ & $\mathrm{D} 1=4.10$ \\
\hline $\mathrm{D} 2=0.28$ & $\mathrm{D} 2=0.25$ & $\mathrm{D} 2=0.31$ & $\mathrm{D} 2=0.27$ & $\mathrm{D} 2=0.29$ & $\mathrm{D} 2=0.33$ & $\mathrm{D} 2=0.32$ & $\mathrm{D} 2=0.31$ \\
\hline BLOCK16 & BLOCK15 & BLOCK14 & BLOCK13 & BLOCK12 & BLOCK11 & BLOCK10 & BLOCK9 \\
\hline $\mathrm{D} 1=2.70$ & $\mathrm{D} 1=3.29$ & $\mathrm{D} 1=5.11$ & $\mathrm{D} 1=3.86$ & $\mathrm{D} 1=1.82$ & $\mathrm{D} 1=2.82$ & $\mathrm{D} 1=3.34$ & $\mathrm{D} 1=1.93$ \\
\hline $\mathrm{D} 2=0.27$ & $\mathrm{D} 2=0.28$ & $\mathrm{D} 2=0.31$ & $\mathrm{D} 2=0.29$ & $\mathrm{D} 2=0.32$ & $\mathrm{D} 2=0.31$ & $\mathrm{D} 2=0.88$ & $\mathrm{D} 2=0.35$ \\
\hline BLOCK1 & BLOCK2 & BLOCK3 & BLOCK4 & BLOCK5 & BLOCK6 & BLOCK7 & BLOCK8 \\
\hline $\mathrm{D} 1=2.75$ & $\mathrm{D} 1=3.13$ & $\mathrm{D} 1=3.50$ & $\mathrm{D} 1=3.00$ & $\mathrm{D} 1=3.77$ & $\mathrm{D} 1=3.11$ & $\mathrm{D} 1=3.27$ & $\mathrm{D} 1=2.23$ \\
\hline D2 $=0.28$ & $\mathrm{D} 2=0.32$ & $\mathrm{D} 2=0.30$ & $\mathrm{D} 2=0.31$ & D2 $=0.29$ & $\mathrm{D} 2=0.26$ & $\mathrm{D} 2=0.29$ & $\mathrm{D} 2=0.32$ \\
\hline
\end{tabular}

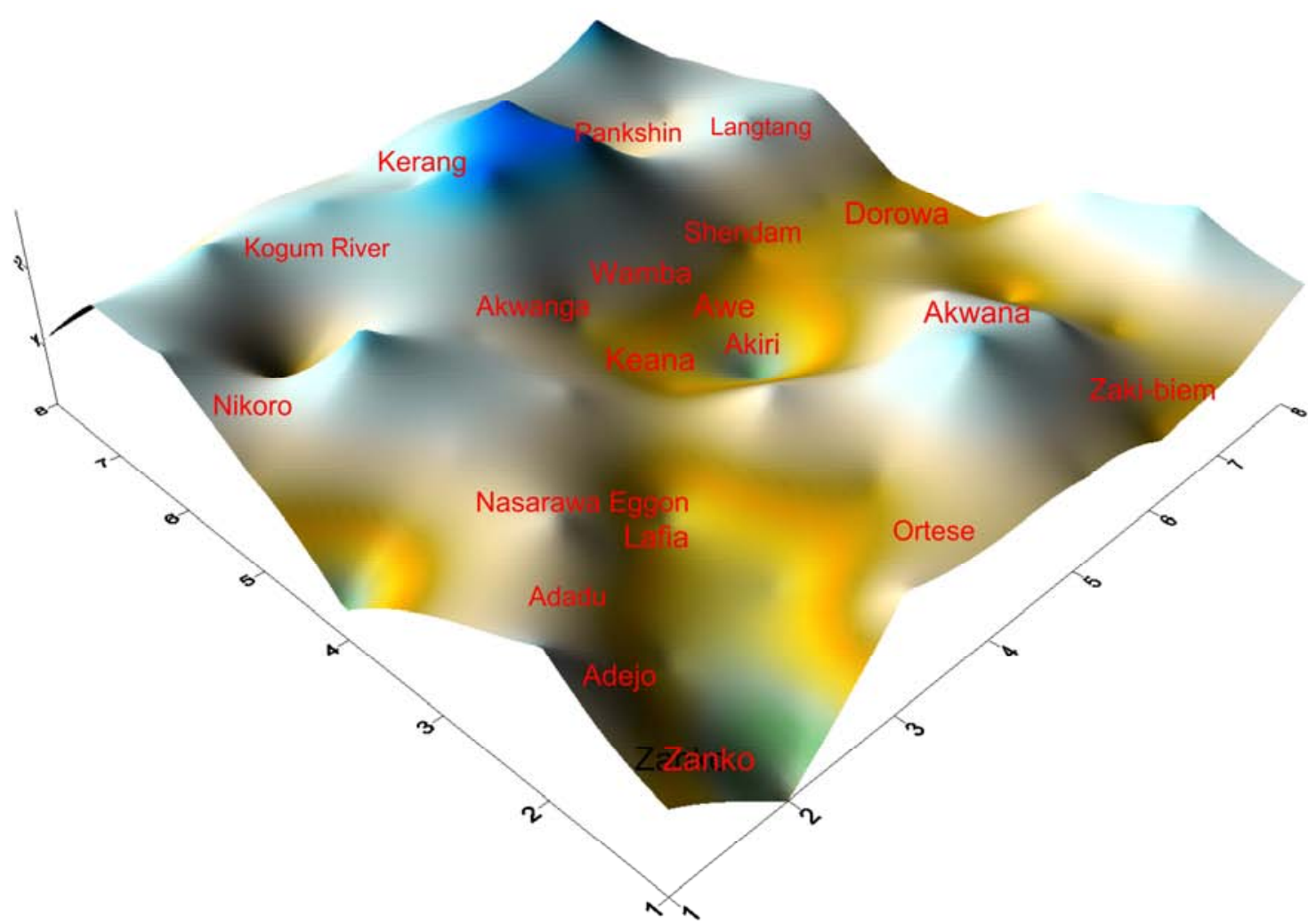

Figure 4. Isometric projection of Depth to the bottom of magnetic sources of the Study Area.

The 2-D modelling technique is a useful tool in the determination of sediment thickness, it can accurately map undulation and give the basement tectonic framework to address the various constraints of depth estimates obtained from spectral analysis. Line paths were drawn on the magnetic residual map across prominent trends and structures that cut across major strike direction identified in the analytical signal map of the area, using a computer program Oasis Montage version 7.5, and the anomalies were modelled using the fore-knowledge of the geology. The magnetic field was calculated iteratively for these geological models, until a good fit was reached between the observed (dots) and calculated (line) profiles. Magnetic field responses computed from the geological models used a declination of 1.7 degrees, and inclination of -9.7 degrees. The regional field strength used is $33,000 \mathrm{nT}$. These averages provide 
adequate characterization of the regional field in the study area. The sediments were assigned the susceptibility of $0.0125 \mathrm{nT}$ in this modelling exercise.

Profiles SAA1 and SAA2 cut across the width of the basement complex rocks at the northern side and the sedimentary section at the southern side. The profiles length is about $220 \mathrm{~km}$ and show good fit between the observed and computed magnetic profiles with an rms errors in the range of 1.45 to $6.5 \%$, Movement along the contacts of the profiles show uplifted block (horst) and down faulted blocks (graben) giving rise to undulation of the basement topography. The horst block flanked by graben on both sides are interpreted as lithologic contacts, joints or faults which have slightly moved relative to the neighbouring blocks. The shallowest depth of $0.2 \mathrm{~km}$ was observed at the basement side and a depth of $6.5 \mathrm{~km}$ was obtained within the graben at the southeastern part.

Profiles BB1 - BB2 are northwest - southeast lines drawn across that cut across northeast - southwest trending anomalies. The two profiles also cut across the width of the basement complex rocks and flanked by the sedimentary rock section at the southern side of the study area, the profiles vary in length between 280 to $300 \mathrm{~km}$, and also show good fit between the observed and computed magnetic profiles with rms between 4.2 to $7.2 \%$, movement along the contacts of the profiles show horst and graben giving rise to undulation of the basement topography in the study area. These are also interpreted as lithologic contacts, joints or faults which have slightly moved relative to the neighbouring blocks. A shallow depth of $0.7 \mathrm{~km}$ was observed at the basement side and the maximum depth of about $6 \mathrm{~km}$ was obtained at the sedimentary section of the study area.

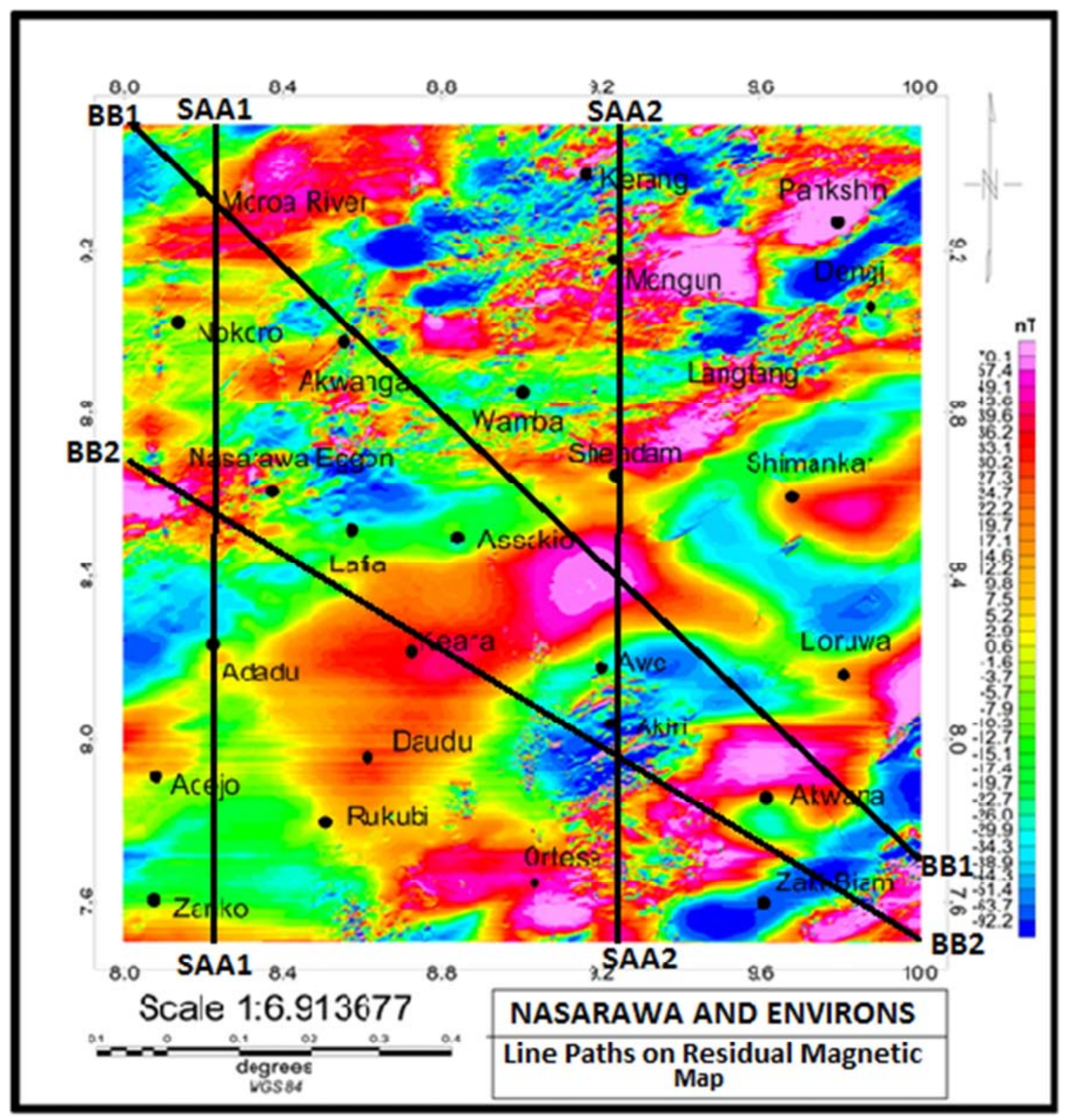

Figure 5. Line Path on the Residual Magnetic Intensity Map for Depth Modeling (Contour interval 0.2km). 

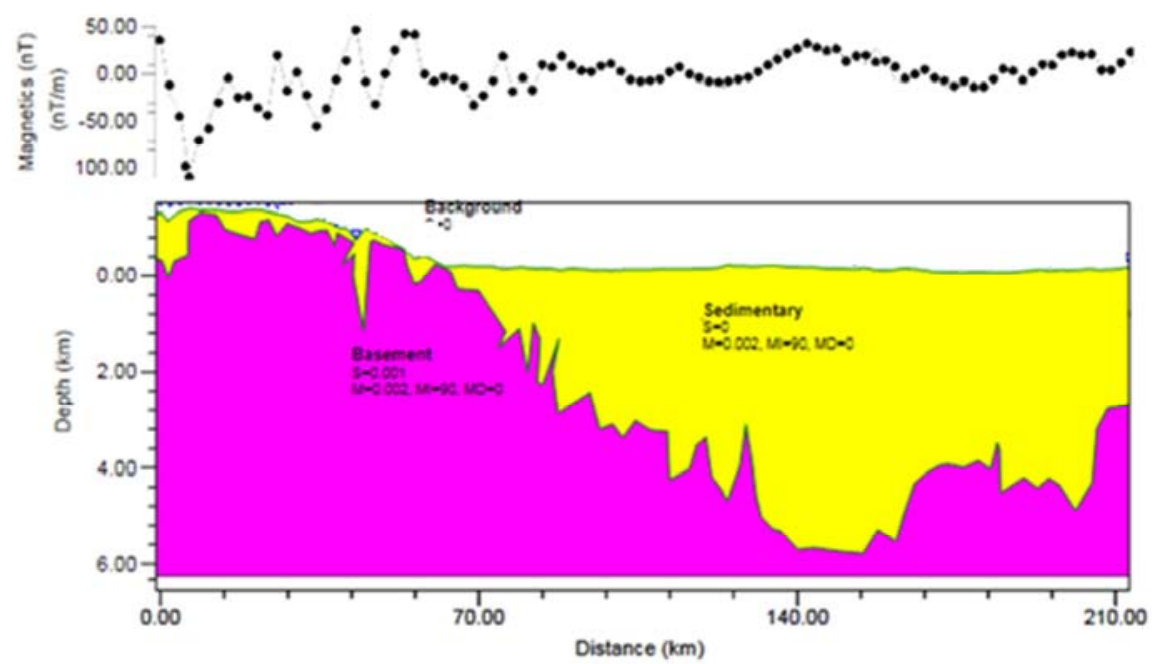

Profile SAA1

Figure 6. Profile SAA1 Sediment thickness obtained D Modeling.
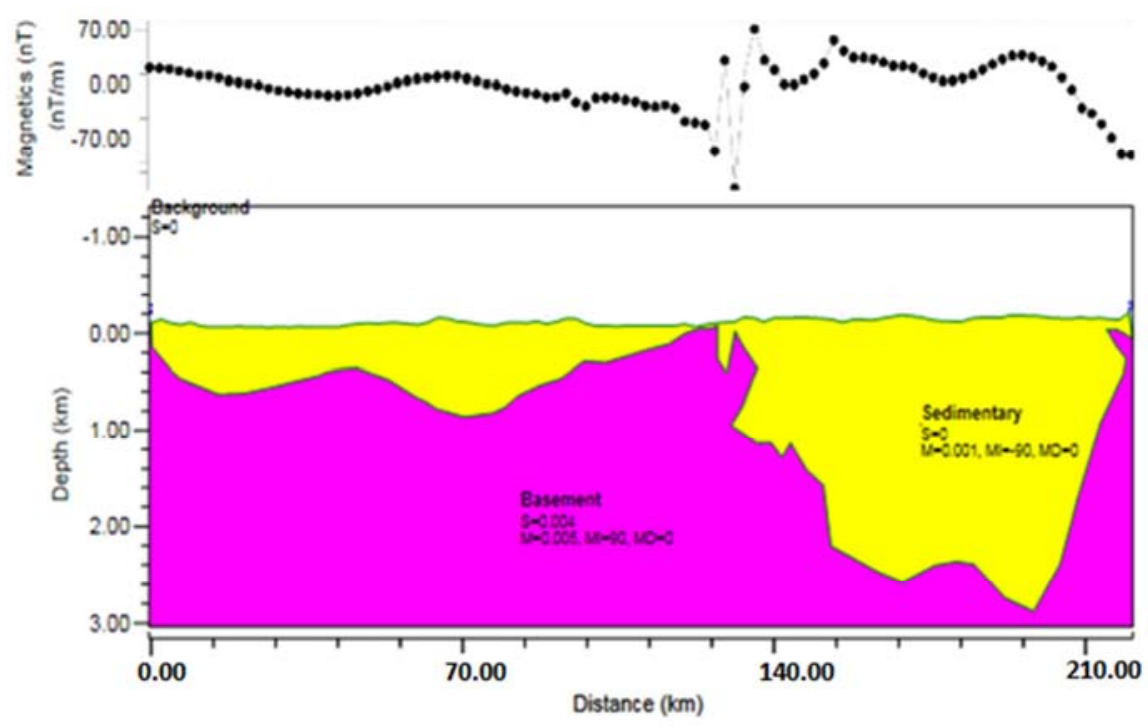

Profile SAA2

Figure 7. Profile SAA2 Sediment thickness obtained from 2-from 2-D Modeling.

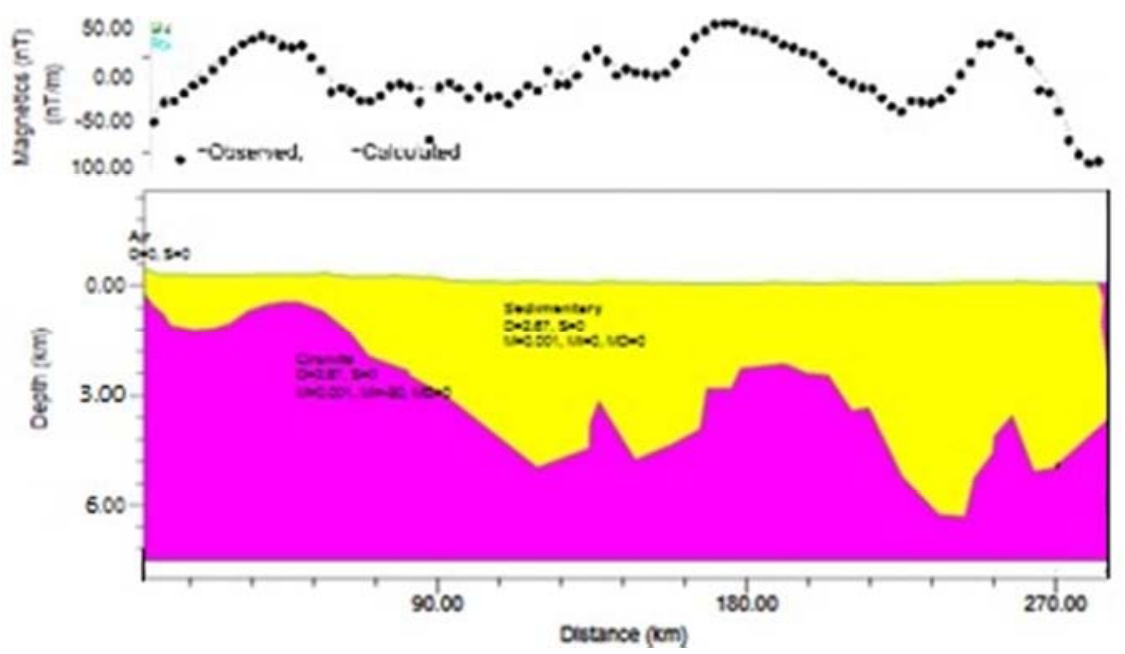

Profile BB1

Figure 8. Profile BB1 Sediment thickness obtained from 2-D Modeling. 


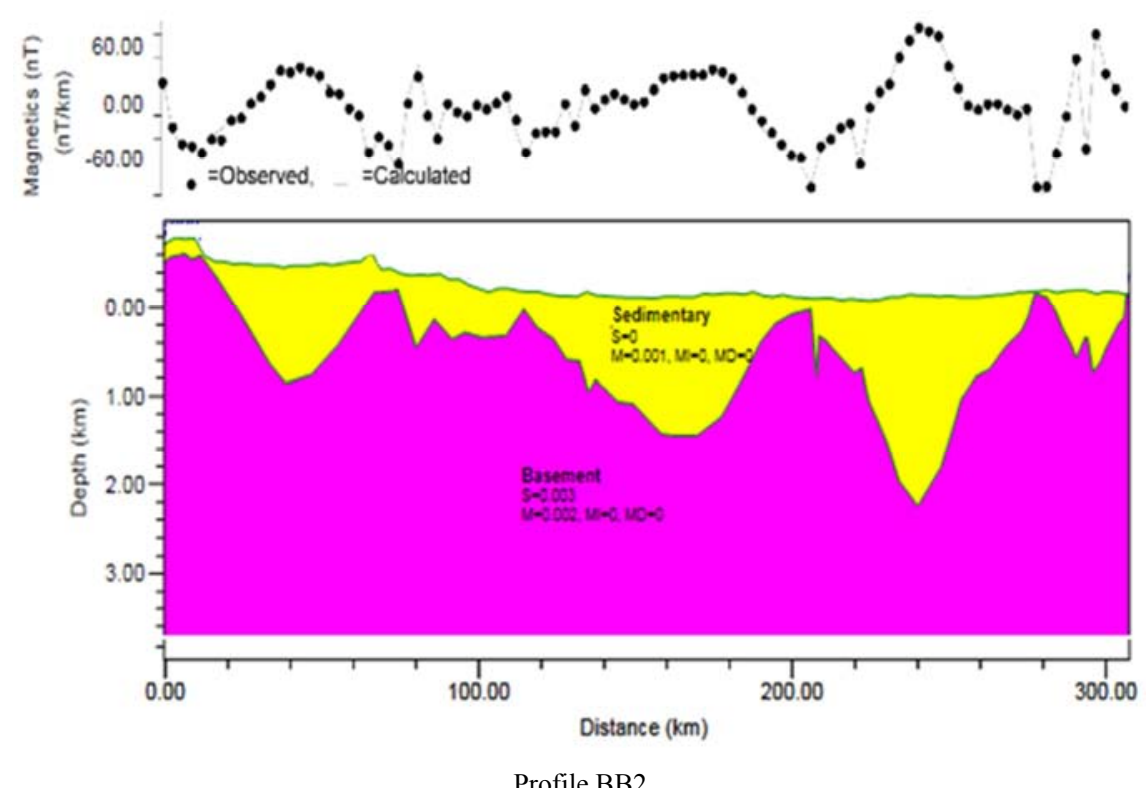

Figure 9. Profile BB2 Sediment thickness obtained from 2-D Modeling.

\section{Discussion of the Results}

The magnetic intensity over parts Nasarawa and Environs showed magnetic signature in the form of colour ranges with red as high and blue as low with clear disposition of different zones with distinct anomaly ranges. The difference in magnetic relief between each two adjacent magnetic highs and lows suggest a comparable variation in Lithology. Bearing this in mind, prominent magnetic relief between two adjacent magnetic highs and lows, elliptical closures and nosing were identified on the magnetic map. These features represent geologic anomalies. The anomalies in the magnetic field of the earth may be considered to arise from three principal sources these are lithologic variation, basement structures and sedimentary sources [5].

Aeromagnetic anomalies over Nasarawa area consist of slow to fast varying types. The former occupy a broader part of the area and is coincident with the sedimentary cover. The latter is a concentrated sequence almost restricted to northern zone of the area and coincident with the basement complex rocks. Few other rapid anomalies exist, particularly at the southeastern part of the area and they are probably caused by basic intrusive within the sedimentary rocks.

Result of Spectral analysis of aeromagnetic data of the study area revealed one and two magnetic anomaly sources depth as shown in table 1 above. These are the deep magnetic anomaly sources and the shallow magnetic anomaly sources. The deep source anomalies vary between $1.09 \mathrm{~km}$ and $5.11 \mathrm{~km}$ with an average depth of $3.10 \mathrm{~km}$ and this represents the magnetic basement depth. The shallow anomaly sources vary from $0.07 \mathrm{~km}$ to $0.42 \mathrm{~km}$ with an average of $0.21 \mathrm{~km}$ and this may be regarded as the magnetic intrusions into the sediment, probably through the magmatic activities and could be responsible for the lead-Zinc mineralization found in the area [19]. The revelation from this study of $3.10 \mathrm{~km}$ average magnetic basement depth is synonymous to depth of over-burden sediment, which is very important as regards to the hydrocarbon generation potential of the area. The depth estimates in some parts of the area are generally hopeful to favour hydrocarbon formation, except at the northern fringes where rocks outcrop on the surface and estimated depth is low. [32] reported that when all other conditions for hydrocarbon accumulation are favourable, and the average temperature gradient of $1^{\circ} \mathrm{C}$ for $30 \mathrm{~m}$ obtainable in oil rich Niger Delta is applicable, then the minimum thickness of the sediment required to achieve the threshold temperature of $115^{\circ} \mathrm{C}$ for the commencement of oil formation from marine organic remains would be $2.3 \mathrm{~km}$ deep. Therefore, the calculated maximum depth of $5.11 \mathrm{~km}$ from the study area is sufficient for oil to generate if other conditions are met. Result from spectral analysis shows the graben nature of the area and indicated the existence of two sub basins in this area. The Middle Benue Trough was considered to be the most prospective area for hydrocarbon within the Trough by [18] with estimated depths to the mature zones of (2-4) km. other researchers which include [23-25] have shown that the area possessed qualities like thick sedimentary sequence, marine source bed, block faulting and suitable traps notable with oil producing regions of the country. [15], using the 1974 data revealed that the basement depths for the Middle Benue Trough from spectral analysis vary across the area, with depth to deeper sources ranging from $1600 \mathrm{~m}$ to $5000 \mathrm{~m}$, while depth to shallow sources ranges from $60 \mathrm{~m}$ to $1200 \mathrm{~m}$ [11] interpreted the 1974 data and estimated a maximum depth of $4.5 \mathrm{~km}$ in the middle Benue Trough. Results of the 2-D spectral analysis by [19], estimated the thickness of sediment in the middle Benue Trough to vary between $2.23 \mathrm{~km}$ and $5.66 \mathrm{~km}$ with an average depth of $3.65 \mathrm{~km}$. From result of the 2-D modelling, it was observed that profiles SAA1 and BB1 have potentials for hydrocarbon accumulation at the sedimentary (southern) section of the study area which corresponds with the Middle 
Benue Trough. The block faulting that produced numerous horst and graben structures in the study area can provide good drainage for generated hydrocarbons. Previous study showed the geology of the area to be associated with the marine Asu River Group which commenced sedimentation in the middle Benue Trough in the Albian, [19].

Further exploration works for coal and hydrocarbon by the Steel Raw Materials Exploration Agency in the ObiAgwantashi-Jangerigeri area in which many boreholes were drilled, revealed High-medium volatile bituminous coals with vitrinite reflectivity in the range of 0.70 to $1.20 \%$ occur within the Awgu Formation [20-22]). The vitrinite reflectance values fall within "oil generation window", in recent time coal beds and shale are now widely known to be major sources of oil and gas and are becoming increasingly exploration targets for hydrocarbon accumulations in many parts of the world. Oil seepages have been widely reported from the Awgu Formation in the southeast and struck in the Ezeaku Formation of Anambra Basin of the Lower Benue Trough. The juxtaposition of sandstone facies of the Keana and Awe formations against the Awgu Formation source rock can lead to some petroleum trappings in this region. Indications of petroliferous residues were also found in the limestones of the Ezeaku Formation in the Middle Benue [27]. Time equivalent marine and paralic sandstones (e.g. the Makurdi Sandstone) and other sandstone bodies within the Awgu Formation are expected to constitute additional reservoirs. The Muri Sandstones, from which oil seepages were reported [1], are lateral equivalents of the Keana and Makurdi Formations. The sandstones are porous in places and could provide excellent reservoirs, of special interest in the search for oil in the Middle Benue Trough is the Keana anticlinoria and Giza synclinorium arising from the Santonian folding episode, present an interesting structural stratigraphical trap setting. The cores of the anticline comprise of highly compacted shales of the Asu River group, with a possible predepositional basement ridge as indicated by $[10]$.

\section{Conclusion}

Sediment thicknesses obtained from the spectral analysis of high resolution aeromagnetic data over parts of Nasarawa and environs revealed one and in most cases two models and hydrocarbon prospects are largely hopeful, because the estimated depth values in the southern part is sufficient for hydrocarbon generation. Secondly the block faulting that produced numerous horst and graben structures in the area can provide good drainage for generated hydrocarbon, thirdly, the existence of Awgu and Ezeaku Formations and coal seams whose vitrinite reflectance values fall within oil generation window and lastly the trapping mechanism presented by the Keana anticlinorium. These results are in agreement with previous studies in the area, more attention should be given to Rukubi in the southwestern and Akwana in the south eastern areas because of favourable geologic features.

\section{Acknowledgements}

The First author wishes to thank Geosoft Inc. South Africa for providing the software which I used for my $\mathrm{Ph}$. D. Research work. Thanks are also due to the department of Geology, Modibbo Adama University of Technology, Yola for the practical application of this work.

\section{References}

[1] Adeleye, D. R, (1975) Nigerian late Cretaceous stratigraphy and paleogeography. AAPG Bull59:2302-2313.

[2] Balogun, O. Y., 2003. Senior Secondary Atlas. 2nd Ed. Longman Nigeria.

[3] Bath, M. (1974) Spectral analysis in Geophysics Elsevier Amsterdam, 20-100.

[4] Bhattacharrya, B. K. (1966). Continuous Spectrum of the total magnetic field anomaly due to rectangular prismatic body, Geophysics, 31, 97-121.

[5] Bird, D. E. (1997): Primer: Interpreting Magnetic data. America Association of Petroleum Geologist Explorer. 18 (5), pp 18-21.

[6] Dobrin, M., \& Savit, C. (1988). Introduction To Geophysical Prospecting (Fourth Edition ed.). Singapore: McGraw-Hill.

[7] Ford, S. O. (1981): The Economic Mineral Resources of the Benue Trough. Earth Evolution Sciences Vol. 1, No. 2, pp154163.

[8] Grant, N. K. (1971). South Atlantic, Benue Trough and Gulf of Guinea Cretaceous triple Junction; Geological Society of American Bulletin 82, pp. 2295-2298.

[9] Johnson, W. W. (1969). A least - Squares method of interpreting magnetic anomalies caused by Two- Dimensional structures. Geophysics, Vol. 34, pp65 -74.

[10] Jones, H. A. (1965): The Geology of Benue Trough. Annual Report Geological Survey Nigeria 1965: 32-37.

[11] Likkason, O. K. (2007). Angular spectral analysis of aeromagnetic data over middle Benue trough Nigeria. Journal Min. Geol. 43 (1); 53-62.

[12] Mishra, D. C. and Naidu, P. S. (1974). Two-dimentional Power spectral analysis of aeromagnetic fields, Geophysics Prop, 22, 345-534.

[13] Nigerian geological Survey Agency. (2006). Geological Map of Nigeria, scale: 1:2, 000, 000 .

[14] Nigerian Geological Survey Agency Abuja. 2009. High Resolution Airborne Geophysical Series-Magnometer Survey Grid Map of Total Intensity (16 sheets). Scale 1: 100,000.

[15] Nur, M. A., Onuoha, K. M. and Ofeogbu, C. O. (1994). Spectral analysis of aeromagnetic data over the middle Benue trough, Nigeria. Jour. Min. Geol. 30 (2):211-217.

[16] Nur, A. (2000). Analysis of aeromagnetic data over Yola arm of the upper Benue trough, Nigeria Jour. Min. Geol. 1 (1):129-142. 
[17] Nur, A., Ofoegbu, C. O. and Onuoha, K. M. (2002). Spectral analysis and Hilbert transform of aeromagnetic data over the Upper Benue Trough, Nigeria. Global Journal of Geological Sciences, Volume 1, No 2, Pages 129-142.

[18] Nwachukwu, J. I. (1985) Petroleum Prospects of Benue Trough, Nigeria, Am Assoc. Pet. Geol., Bull., 69 (4), 601609Mishra, D. C. and Naidu, P. S; 1974. Two-dimentional Power spectral analysis of aeromagnetic fields, Geophysics Prop, 22, 345-534.

[19] Nwonsu O. B, Umego M. N, Onuba L. N., (2013). Spectral Re-Evaluation Of The Magnetic Basement Depth Over Parts Of Middle Benue Trough Nigeria Using HRAM International Journal Of Scientific and Technology Research Volume 2, Issue 10, Issn 2277-8616.

[20] Obaje N. G (1994) Coal petrography, microfossils and paleoenvironments of Cretaceous coal measuresin the Middle Benue Trough of Nigeria. Tuebinger Mikropalaeontologische Mitteilungen 11,1-165.

[21] Obaje, N. G. (1997): Petrographic evaluation of the coking potential of the Cretaceus Obi/Lafia coal deposits in the Benue Trough of Nigeria ZcitsclirififurAngc'n'andte Geologic, VoI. 43, pp. 2 8-223.

[22] Obaje, N. G. and Hamza, H. (1999): Liquid hydrocarbon source rock potential of Cretaceous coals and coal measures in the Middle Benue Trough of Nigeria. Jniernatzonal. Jow'nalof Earth Sciences, Vol. 89 (1), pp. 63-79.

[23] Ofoegbu, C. O. (1984) Aeromagnetic anomalies over the lower and middle Benue Trough Nigeria; Nigeria Journal of mining and geology Vol. 21, pp. 103- 108.
[24] Ofoegbu, C. O. (1985). A review of the geology of the Benue Trough of the Nigeria; Journal of African Sciences, Vol. 3 pp. 285-291.

[25] Ofoegbu, C. O. (1986). A preliminary result of a pseudogravity study of the Benue Trough, Nigeria. J. Afr. Earth Sci; 5: 187- 192.

[26] Ofeogbu, C. O. and Onuoha, K. M. (1991). Analysis of magnetic data over the Abakaliki Anticilionrium of the lower Benue trough, Nigeria. Marine and Petrol. Geol. 8:174-183.

[27] Offodile. M. E. (1976). The Geology of the Middle Benue, Nigeria. Palaentological Institute, University Uppsala, Special Publication,, 4:pp 1-166.

[28] Skeels, D. C. (1967): What is Residual Gravity? Geophysics, 32: $872-876$

[29] Spector, A. and Grant, T. S. (1970). Statistical models for interpreting aeromagnetic data. Geophysics.

[30] Udensi, E. E., Osazuwa, I. B. and Daniyan, M. A. (2000). Production of a composite aeromagnetic map of the NupeBasin. Nigeria Journal of Science, Technology and Mathematics Education. Pages 150-159.

[31] Udensi E. E, Osazuwa, I. B., (2004) Spectral determination of depths to magnetic rocks under the Nupe Basin, Nigeria. NAPE Bull 17:22-27.

[32] Wright, J., Hastings, D., Jones, W., \& Williams, H. (1985). Geology and Mineral Resources of West Africa. London: George Allen and Unwin publishers Ltd. 